\title{
Performance analysis of a floating power plant with a unidirectional turbine based power module
}

\author{
Prasad Dudhgaonkar ${ }^{1}$, Kedarnath S. ${ }^{2}$, Biren Pattanaik ${ }^{1}$, Purnima Jalihal ${ }^{1}$, Jayashankar V., ${ }^{2, *}$ \\ ${ }^{1}$ National Institute of Ocean Technology, Chennai, India \\ ${ }^{2}$ Indian Institute of Technology Madras, Chennai, India
}

*Corresponding author. Tel: + Tel: +91 4422574427, Fax:+91 4422570509, E-mail: jshankar@ee.iitm.ac.in

\begin{abstract}
A major attraction of a floating wave power plant as opposed to a fixed Oscillating water column (OWC) plant is in the cost of construction. The price paid is in the lower efficiency of conversion in the hydrodynamic stage. This puts onus on the subsequent power module stage in achieving an efficiency that is necessary for a commercial plant. A new backward bent ducted buoy (BBDB) was designed in which the power module is a twin unidirectional turbine. Basic experimentation on the power module is done on a turbine with $165 \mathrm{~mm}$ diameter and characterized with bidirectional flow with widely varying flow rates. The efficiency is shown to be better than $68 \%$ over the expected working range. The details of a plant producing $50 \mathrm{~kW}$ for Indian conditions is described. The range of powers over which a BBDB structure compares with a fixed OWC is highlighted.
\end{abstract}

Keywords: Wave energy, floating power plant, backward bent ducted buoy.

\section{Introduction}

The oscillating water column (OWC) principle is an attractive approach to convert wave energy into electrical energy as exemplified by operational plants in several countries [1]. As of today it is reasonable to expect a wave to wire efficiency of about $24 \%$ with a fixed OWC device [2]. Of this, the OWC efficiency would be about $60 \%$, and the power module (comprising bidirectional turbine and generator) would be about $40 \%$. One aspect of the fixed OWC is that the structural cost could lie between 70 to $85 \%$ of the overall cost [3]. This has motivated the development of floating OWCs which promise reduced cost with an accompanying reduction in efficiency in the hydrodynamic stage. The largest of such structures was the Japanese Mighty Whale [4]. While laboratory results predicted a best efficiency of $50 \%$ in the hydrodynamic stage, practical measurements showed that the best efficiency was about $30 \%$. Hence the overall wave to wire efficiency was closer to $15 \%$. There have been continuous attempts to improve the efficiency of floating OWCs and the backward bent ducted buoy (BBDB) is one such attempt [5]. In this work we show that an improved power module for the BBDB with variable speed twin unidirectional turbines can achieve $65 \%$ efficiency and thus make the floating structure attractive in spite of the lower hydrodynamic efficiency.

\section{The Backward Bent Ducted Buoy (BBDB)}

The Backward Bent Ducted Buoy (BBDB) has been conceived as a relatively low cost wave energy device to convert wave energy into electricity. The BBDB has a backwardly inclined oscillation water column, which has been proved to be more effective than a forwardly inclined one. It uses an oscillating column of water in reverse $\mathrm{L}$ shaped chamber or duct, such that the open mouth of the duct is away from the incident waves. The horizontal limb has an opening to the sea and is submerged under water. The vertical limb traps a column of air at the upper region of the duct and a regulated vent allows air to pass in and out under cyclic pressure and partial evacuation of air due to oscillating water surface. The enclosed water column is, not influenced by the wave movements around the buoy, whereby it oscillates 
relative to the wave motion moving the buoy itself. The air current, which arises, drives an air turbine installed above the water column. This airflow becomes a means to produce power. Fig. 1 shows a BBDB which was initially deployed for testing without a power module. It had an equivalent orifice in order to simulate a turbine. The dimensions of the model were determined after model studies as reported in [6]. The Indian conditions require a zero crossing period of about 8 seconds and a significant wave height of $1.2 \mathrm{~m}$ yielding average incident energy of $6.3 \mathrm{~kW} / \mathrm{m}$. The overall design is based on an improvement in the power module in the work reported in [7].

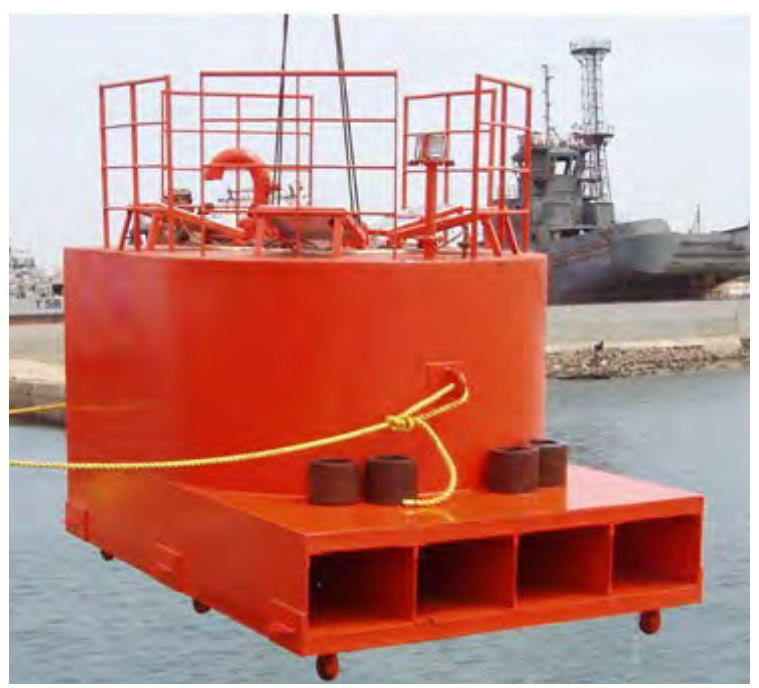

Fig.1. The BBDB being deployed with an orifice for charactering hydrodynamic performance

\section{Basic simulations on fixed guide vane and unidirectional impulse turbines}

The design of the BBDB described in [7] was based on a fixed guide vane impulse turbine. It was concluded that an optimum turbine diameter of $1.5 \mathrm{~m}$ would yield a power output of 30 $\mathrm{kW}$ with $\mathrm{H}_{\mathrm{s}}=2.25 \mathrm{~m}$ and $\mathrm{T}_{\mathrm{z}}=8.5 \mathrm{~s}$ where $\mathrm{H}_{\mathrm{s}}$ and $\mathrm{T}_{\mathrm{z}}$ are the significant wave height and zero crossing period respectively. We show that an equivalent power module with a twin unidirectional turbine topology [8] would substantially improve the efficiency of the power module and thus the overall power conversion. In order to validate the concept, studies are done in a turbine of diameter $165 \mathrm{~mm}$ coupled to a $375 \mathrm{~W}, 3000 \mathrm{rpm}$ dc generator. An oscillatory flow rig is used to characterize the performance. The diameter was based on two criteria: The oscillatory flow rig is sufficient for characterizing its performance over the entire flow regime and more importantly the damping offered by the turbine matches that of the orifice used in the BBDB hydrodynamic test. This is shown in Fig. 2 which portrays the pressure- flow behavior of the $165 \mathrm{~mm}$ unidirectional turbine (UDI), a $165 \mathrm{~mm}$ fixed guide vane impulse turbine (FGV) and orifices ranging from $52.5 \mathrm{~mm}$ to $77.9 \mathrm{~mm}$ in diameter. As is known the best hydrodynamic efficiency occurs when the area ratio between the orifice and the OWC water plane lies in the $1 / 100$ to $1 / 150$ range. The $165 \mathrm{~mm}$ turbine meets this requirement. Fig. 3 shows a comparison of the performances of FGV turbines and UDI turbines estimated from steady state tests. The comparison is in terms of the efficiency, output shaft powers and the operating flow coefficient $\phi$. Both machines operate at $3000 \mathrm{rpm}$. A fixed speed of operation is initially considered with an induction generator as an option. It is seen that the UDI turbine has a higher efficiency than the FGV turbine. A more important result is established based on a careful study of Fig. 3. It can be seen that the efficiency of the UDI turbine drops when the pneumatic power increases. One solution to remedy this aspect is to consider a variable speed generator as opposed to a fixed speed one. Accordingly Fig. 4 
shows the performance of the UDI for various speeds from $1500 \mathrm{rpm}$ to $3500 \mathrm{rpm}$. The remarkable result that emerges is that with a variable speed machine, the efficiency can be made to remain at about 0.7 over the entire range of operation from $4 \mathrm{~W}$ to $160 \mathrm{~W}$. Further the variation in speed is within the range feasible with doubly fed induction machines or permanent magnet synchronous machines.

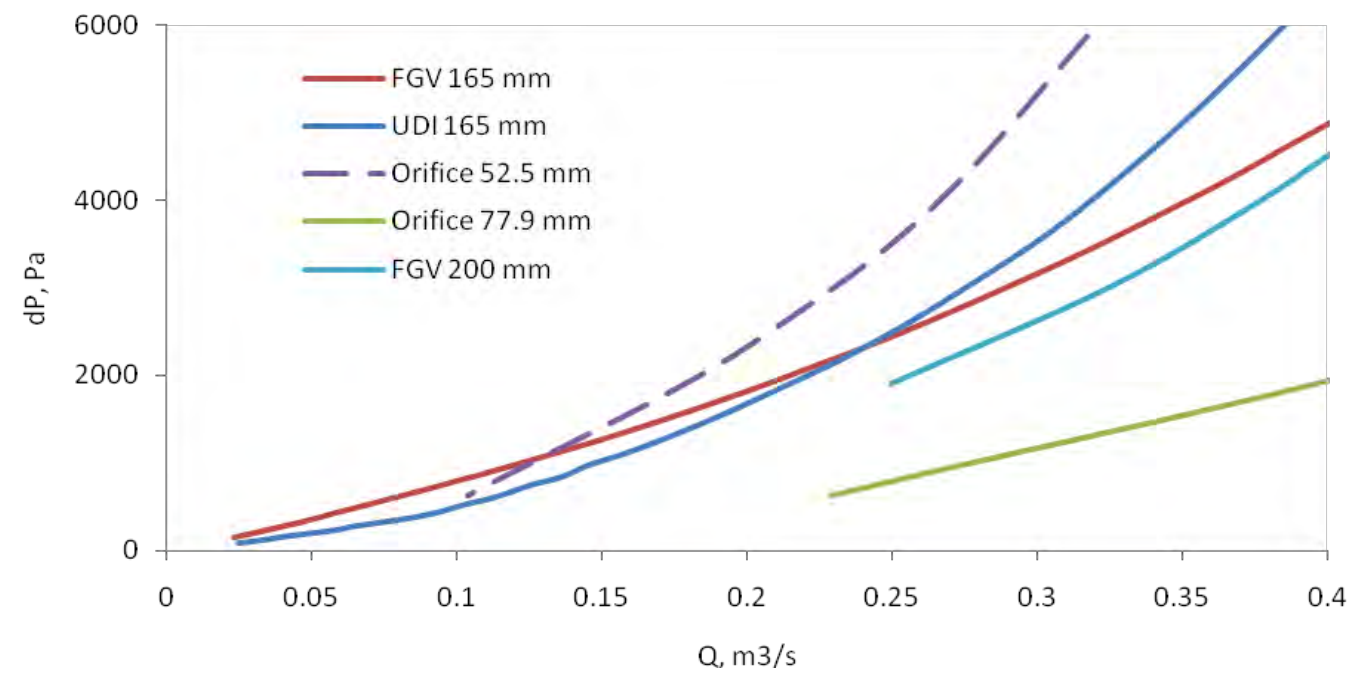

Fig.2: Differential pressure across fixed guide vane impulse turbine and unidirectional impulse turbine for diameter $165 \mathrm{~mm}$ for different flow rates (3000 rpm)

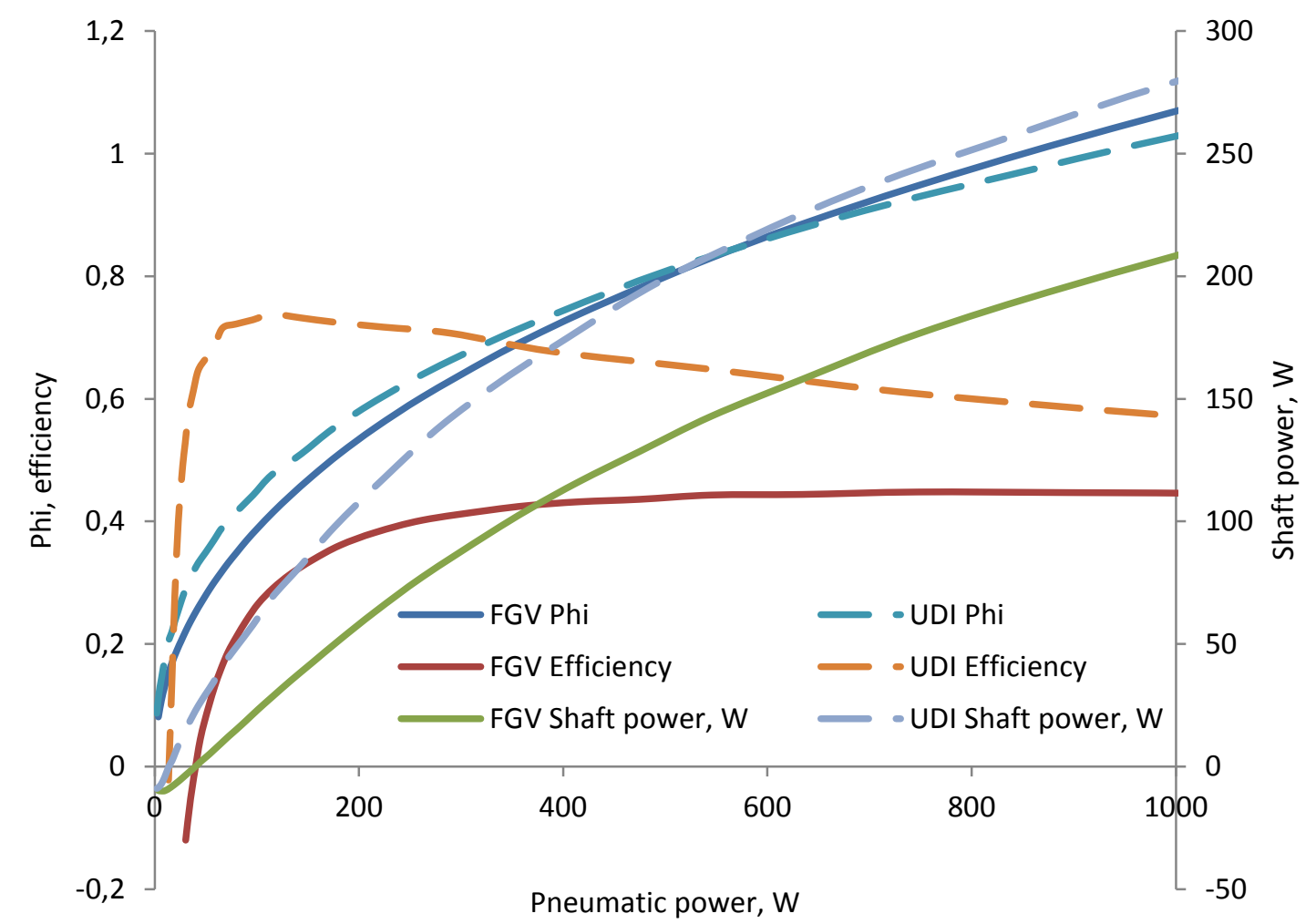

Fig. 3: Comparison of performance of fixed guide vane impulse turbine and unidirectional impulse turbine for diameter $165 \mathrm{~mm}$ (3000 rpm) 


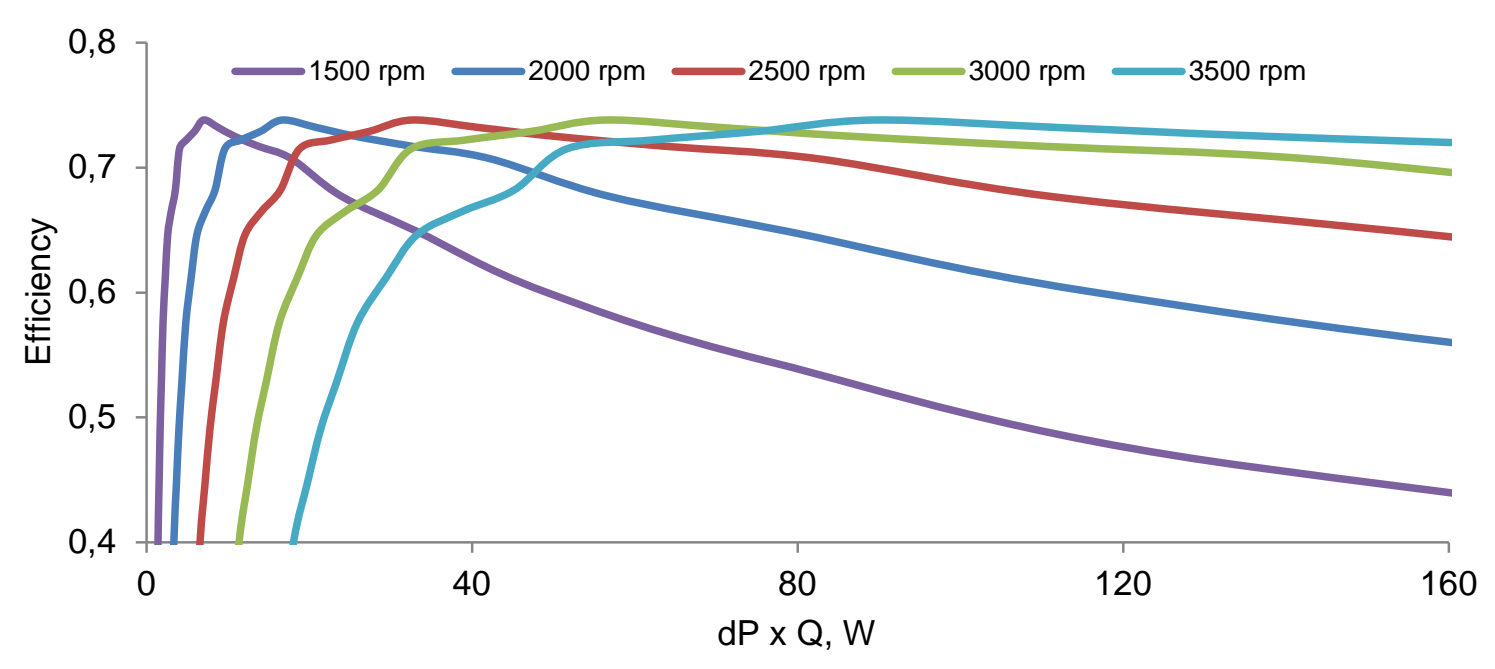

Fig. 4. Estimated performance characteristics for unidirectional impulse turbine of $165 \mathrm{~mm}$ diameter over a range of speeds

\section{The power module for the BBDB}

The prototype BBDB recently made for experiments in Japan had a length of $25 \mathrm{~m}$, breadth of $5.25 \mathrm{~m}$ and a draft of $10 \mathrm{~m}$ [7]. It could produce a peak output of $30 \mathrm{~kW}$ at $\mathrm{Hs}=2.25 \mathrm{~m}$ with a $1.5 \mathrm{~m}$ FGV turbine. We now consider the use of a $1.5 \mathrm{~m}$ UDI turbine for the same purpose. Fig. 5 shows the comparison. Fig. 5 a compares the shaft output from the two classes of turbines with speeds of $300 \mathrm{rpm}$ and $600 \mathrm{rpm}$ with input powers up to $400 \mathrm{~kW}$. The corresponding efficiencies are shown in Fig 5 b. Fig. 5 b again highlights the importance of variable speed operation for the UDI turbine.

The next section concerns the experimental validation of the UDI concept.

\section{Experimental setup for validation of the UDI turbine}

The basic experimental setup for oscillatory flow studies was described in [8] wherein it was also shown that induction generators could be used for the power module. In this work a slightly different approach was used. Two pipe sections were independently coupled to the common oscillatory flow rig. One of them housed a $165 \mathrm{~mm}$ UDI turbine with a $3000 \mathrm{rpm}$, $180 \mathrm{~V}, 375 \mathrm{~W}$ dc generator. The other housed an orifice in conjunction with a fluidic diode (bluff body) as shown in Fig. 6. This was to ensure the matching of the turbine damping to that of an appropriate orifice and also to ensure that the intake stroke provides flow to the orifice and the exhaust stroke vents air through the turbine. It can be appreciated that several basic experiments on the performance of various shapes of fluidic diodes could also be tested with this arrangement. In effect it tests the ability of passive fluidic diodes in controlling flow. 


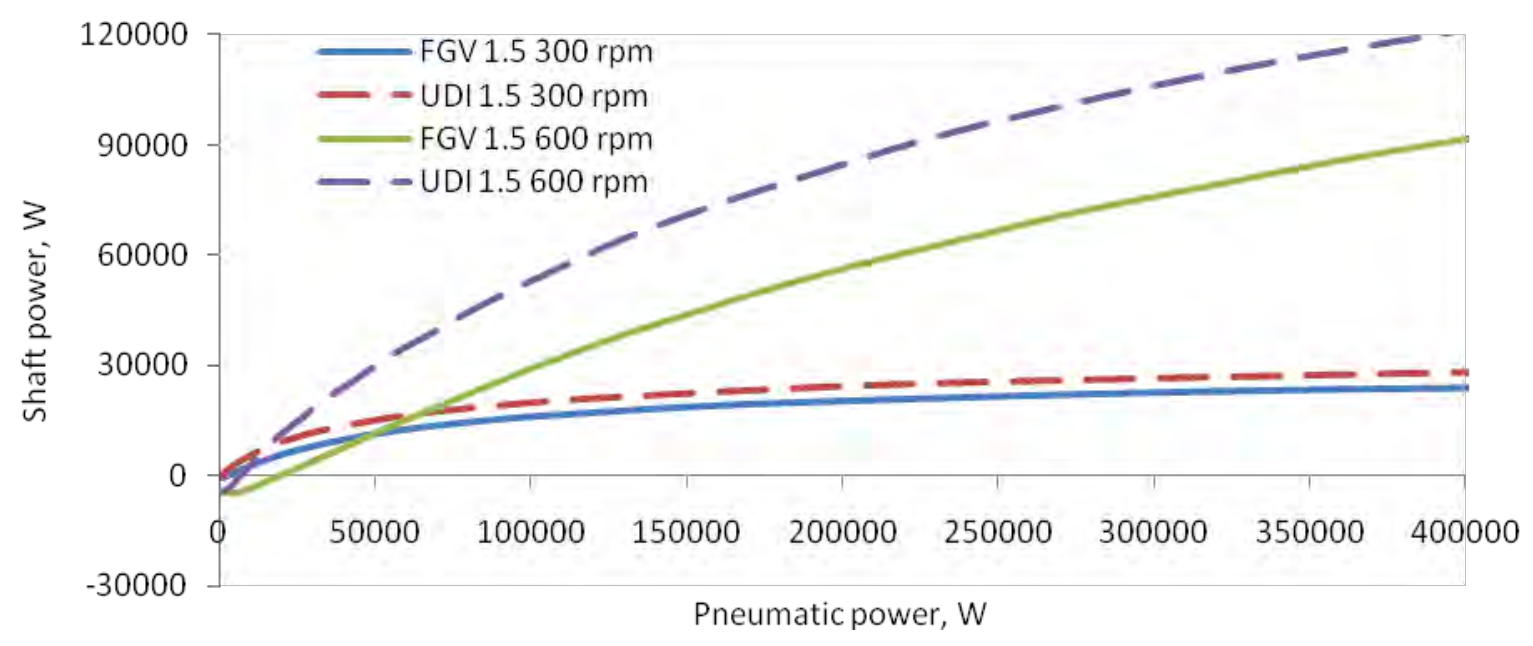

(a)

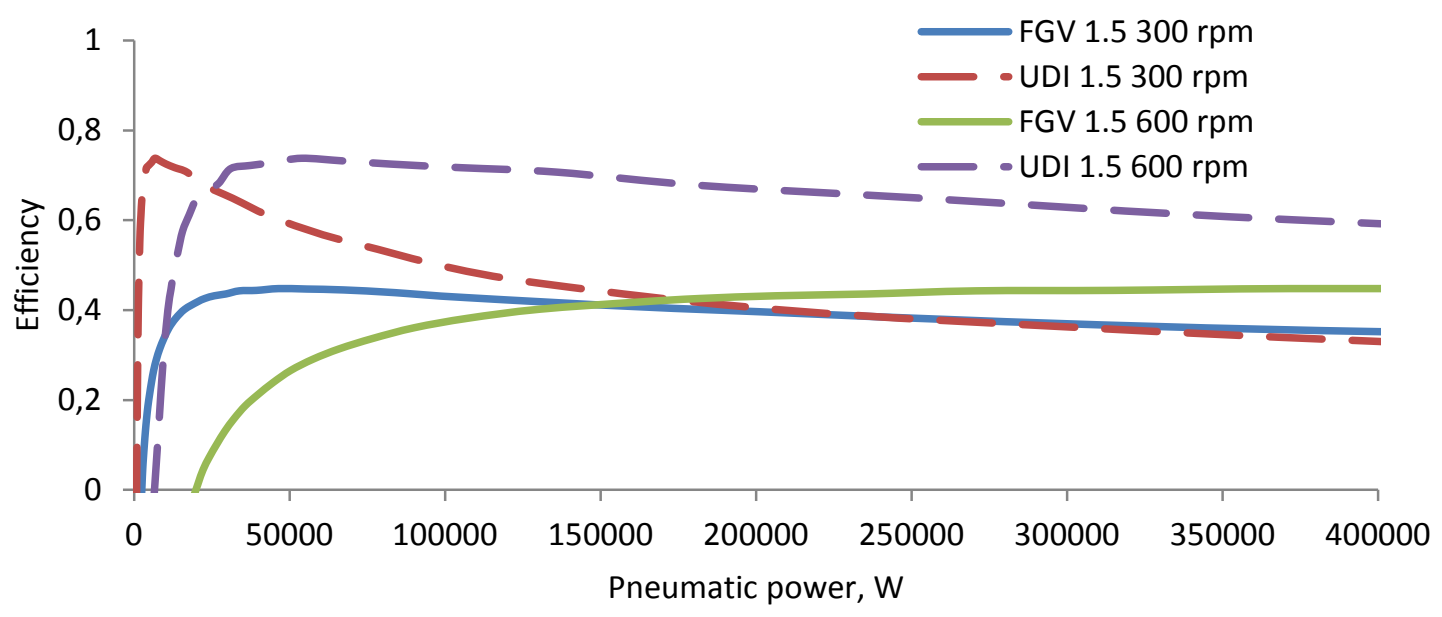

(b)

Fig.5: Comparison of performance of fixed guide vane turbine and unidirectional flow turbine for diameter $=1.5 \mathrm{~m}$ for different speeds

Figure 6 presents the comparison of the performance of a FGV turbine of diameter $1.5 \mathrm{~m}$ presented in [7] with the estimated performance of a UDI turbine of the same diameter. It can be noted that the variable speed UDI turbine can deliver up to 20 to $30 \%$ more power over FGV turbine. Also the overall wave to wire efficiency of the BBDB with UDI turbine is higher for the entire range of operation.

The quantities measured were pressure across the impulse turbine and the orifice, the turbine inlet duct pressure, the turbine speed, the generator voltage, load current.

\section{Pressure measurements}

The differential pressure across the turbine and orifice were measured using calibrated differential pressure transmitters (STD 120) made by M/s. Honeywell. 


\section{Voltage and Current measurements}

The generator terminal voltage was measured using voltage transducers made by M/s. LEM. The load current was measured using current sensors by M/s. LEM, USA. All of these devices were calibrated before use, with accuracies better than $1 \%$.

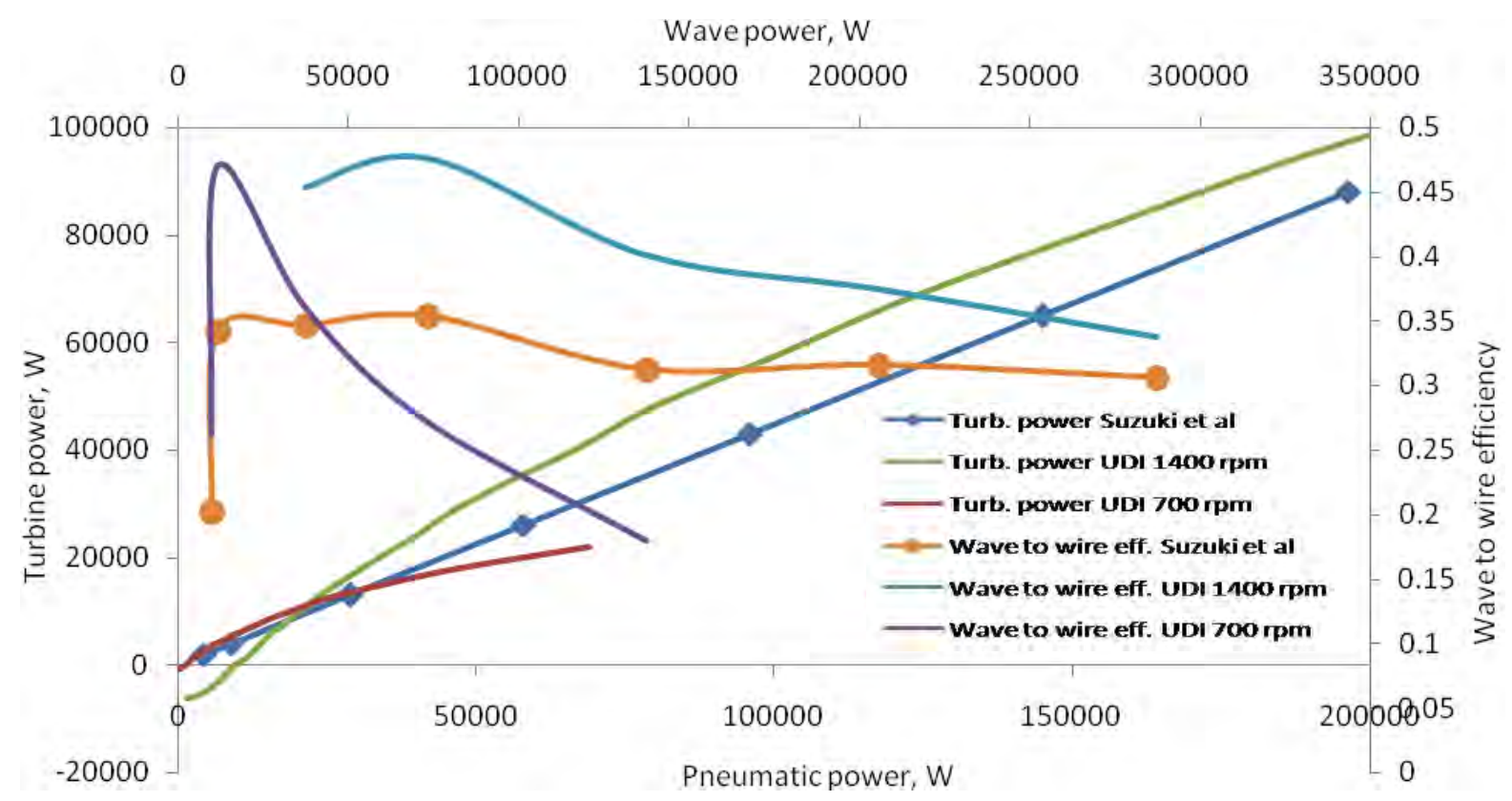

Fig. 6: Estimated power output of a 1.5 m diameter unidirectional impulse turbine

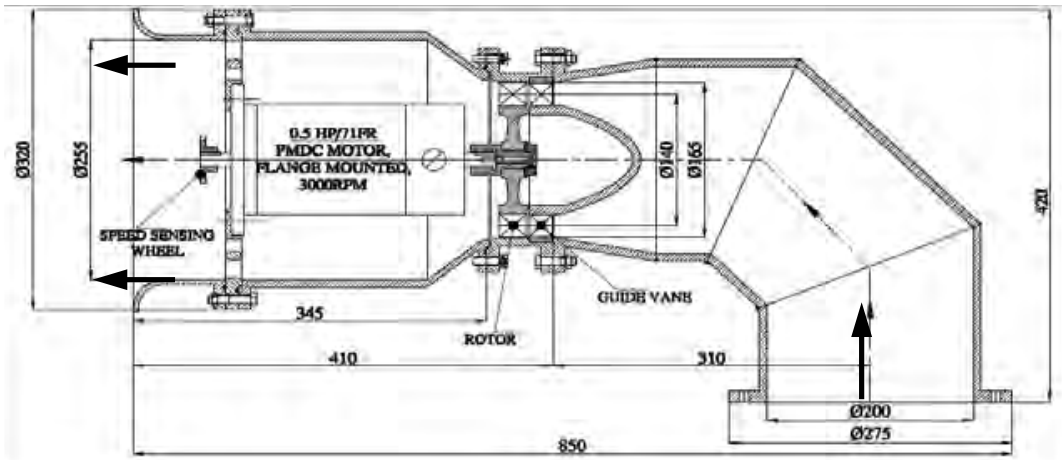

(a)

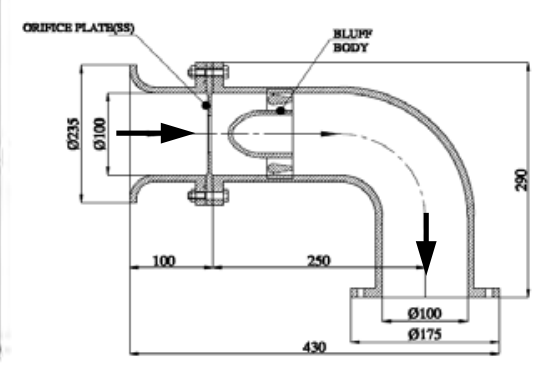

(b)

Fig. 7 : 165 diameter unidirectional flow turbine for exhaust and air vent with bluff body for intake

\section{Power and speed}

The electrical power was estimated from the generator terminal voltage and load current. The turbine speed was estimated from the generator terminal voltage to within $2 \%$ error.

\section{Data acquisition}

All the data pertinent to the evaluation were logged by a data acquisition system (DAQ, USB 6215, National Instruments) at $1 \mathrm{kS} / \mathrm{s}$. Low pass filters were employed to remove noise in the signals. 
Fig. 8 shows one typical result. It primarily validates the notion of using twin UDI turbines by ensuring appropriate intake and exhaust flow though the turbine and orifice respectively and also quantitatively establishes the efficiency of the turbine. Fig. 8 shows the output from the generator for various stroke lengths of the piston that drives the oscillatory flow. The peak pressure drop observed on the test rig across a $30 \mathrm{~mm}$ diameter orifice matched with the peak pressure drop across the turbine.

In effect the experiments and simulation confirm the likely improvements in BBDB performance by replacing the FGV turbine with a UDI turbine.

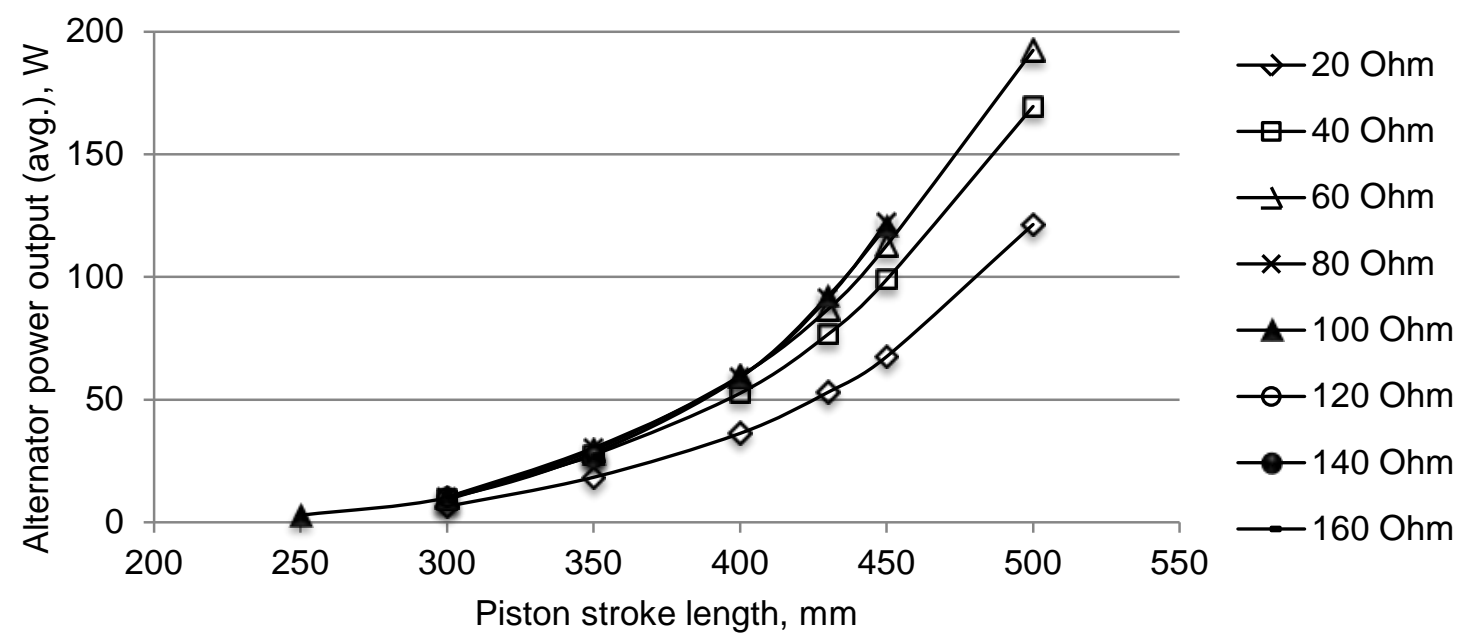

Fig. 8. Average power output of alternator vs. piston stroke length vis-à-vis electrical resistance

\section{Conclusions}

A power module based on the twin unidirectional impulse turbine topology can substantially improve the efficiency of a BBDB. Experiments on a $165 \mathrm{~mm}$ turbine validate the claims of improved efficiency. A $1.5 \mathrm{~m}$ turbine can produce about $50 \mathrm{~kW}$ in comparison with $30 \mathrm{~kW}$ from a fixed guide impulse turbine for the same wave excitation. Variable speed operation is a must in order to retain the high efficiency over the range of operation. There exists a strong case for floating OWCs in several applications involving powers in the tens of $\mathrm{kW}$ range.

\section{References}

[1] Heath, T., Whittaker, T.J.T \& Boake, C.B.; The design, construction and operation of the LIMPET wave energy converter, Wave Energy 2000, 2000

[2] Ohno H., Funakoshi T., Saito K., Oikawa K., and Takahashi S., "Interim report on the Second Stage of Field Experiments on a Wave Power Extracting Caisson In Sakata Port," ODEC, 1993, pp. 173-182.

[3] Marine Energy Challenge: Oscillating Water Column wave energy converter evaluation report, (C) The Carbon Trust 2005.

[4] Research and development of technology on wave energy utilisation, Jamstec 2004

[5] Masuda Y et al "The BBDB an improved floating type wave power device”, Proceedings Ocean 88, pp 1067-1072. 
[6] A.G. Pathak, A. Subramaniam, “ Performance studies on a scaled model BBDB under regular and random waves ”, Proceedings ISOPE, 1999 pp 139-141.

[7] Suzuki et al "Performance of OWC type floating wave power plant employing impulse turbine” $3^{\text {rd }}$ International conference on ocean energy, Bilbao, 2010.

[8] Mala K., Jayaraj J., Jayashankar V. et al., "A twin unidirectional impulse turbine topology for OWC based wave energy plants - Experimental validation and scaling," Renewable energy 36, 2011, pp. 307-314. 